\title{
Amar sólo por vencer: la "picaresca" de María de Zayas
}

\author{
Amar sólo por vencer: \\ The "Picaresque" of María de Zayas
}

FERNANdo RodríGUEz Mansilla

Este trabajo analiza la novela Amar sólo por vencer de María de Zayas (incluida en sus Desengaños amorosos, 1647) a partir del motivo narrativo del matrimonio desigual: el de un pícaro disfrazado de caballero que seduce a una dama bajo promesa de matrimonio. Zayas recrea un episodio típicamente picaresco y lo pone al servicio de un discurso protofeminista en donde dramatiza el rol de la dama, víctima de la venganza familiar. Esta presencia de la picaresca en Zayas obedece posiblemente a su contacto literario con Alonso de Castillo Solórzano, cuyas historias picarescas aparecen referidas en varios pasajes de Amar sólo por vencer. Nos hallamos así ante una versión original de la "picaresca" en la obra narrativa de María de Zayas.

PALABRAS ClaVE: María de Zayas, novela picaresca, Amar sólo por vencer, novela corta, Alonso de Castillo Solórzano.

This article explores the short novel Amar sólo por vencer by María de Zayas (included in her book Desengaños amorosos, 1647), through the literary topic of the unequal wedding: a rogue, pretending to be a nobleman, seduces a noblewoman with the promise of marriage. In this piece, Zayas recreates a typical picaresque episode within a protofeminist discourse, depicting a young woman as a victim of a familiar vengeance. This picaresque influence in Zayas' writing is probably due to her contact with Alonso de Castillo Solórzano, whose picaresque narratives Zayas is apparently recalling in several passages of Amar 
sólo por vencer. As a result, this is an original "picaresque" story crafted by María de Zayas.

KEYWORDS: María de Zayas, picaresque novel, Amar sólo por vencer, short novel, Alonso de Castillo Solórzano.

Fecha de recepción: 8 de junio de 2015

Fecha de aceptación: 27 de agosto de 2015 


\author{
FERnANDO RodRÍGUEZ Mansilla \\ Hobart and William Smith Colleges \\ mansilla@hws.edu
}

\title{
Amar sólo por vencer: la "picaresca" de María de Zayas
}

Este trabajo aborda el análisis de la novela Amar sólo por vencer de María de Zayas (incluida en sus Desengaños amorosos, 1647) a partir del motivo narrativo del matrimonio desigual: el de un pícaro disfrazado de caballero que seduce a una dama para gozarla, bajo la promesa de matrimonio. Zayas, como novelista, recrea un episodio típicamente picaresco y lo pone al servicio de un discurso protofeminista en el que se dramatiza el rol de la dama víctima de la venganza familiar.

En términos de prestigio social, tenemos dos tipos de matrimonio desigual. El primero es el del cuento de hadas y (aún) de varias telenovelas: joven rico y noble que se casa con una joven humilde. Una historia de Don Quijote de la Mancha exalta esta posibilidad: la de una muchacha hija de labradores ricos (digamos Dorotea) que puede aspirar a un noble, segundón, si no de título (don Fernando): aunque éste al inicio sólo pretendía gozarla y olvidar su promesa, ella lo persigue, lo encuentra, se pone a sus pies y le implora, llorando, que cumpla su palabra, que ese matrimonio no va a deshonrarlo, porque la nobleza se transmite por vía masculina. De este primer tipo de matrimonio desigual no me interesa hablar aquí, porque acaba bien. Me enfocaré en el segundo tipo, el que acarrea el conflicto: joven noble y rica con galán pobre y plebeyo. ¿Quién más inapropiado como galán casadero, por indigno, que un pícaro? El matrimonio en la novela picaresca siempre 
anuncia lo peor: una progenie marcada por la infamia y la "mala sangre", cuando no la ocupación de "marido cornudo". ${ }^{1}$ Recuérdese que los pícaros iniciales solían ser malos seductores o casarse mal. Pasamos de un cornudo como Lázaro a un ingenuo galán, improvisado y accidental, sólo episódico, en el Guzmán de Alfarache (cuyo protagonista también termina como proxeneta de su mujer).

Sólo a partir del Buscón, el episodio del pícaro que sueña con un buen partido se vuelve lugar común del género. El matrimonio desigual desde entonces se vuelve un asunto picaresco más. El bachiller Trapa$z a$ de Alonso de Castillo Solórzano no tiene mejor fortuna que Pablos, pero ya es un pícaro tan guapo como cualquier caballero convencional, que nunca logra su cometido de matrimonio con dama alguna pero campea por la corte con ese objetivo, y hasta logra infiltrarse en ambientes refinados. ¿Cómo es posible este cambio? Debemos considerar el impacto de la novela corta y su estética de refinamiento y galantería. El pícaro guapo y educado, tan perfecto que hasta puede razonablemente pasar por noble, es una marca registrada de Castillo Solórzano; gran diferencia frente a los pícaros canónicos (Lázaro, Guzmán y Pablos), quienes se caracterizaban más bien por una fealdad y ridiculez que los descartaban de antemano (de allí que sus lances no sólo fracasen sino que sean risibles). Fue precisamente Castillo Solórzano el cultor más prolífico de esta picaresca con ribetes cortesanos que se desarrolla a partir de 1620, de la mano de obras de autores menos conocidos, pero que van marcando una tendencia. Citaré sólo dos de ellos que pueden haber desbrozado el camino tanto para Castillo Solórzano como para Zayas en sus retratos de pícaros galanes que pueden suponer, realmente, un peligro para chicas en edad de merecer.

Consideremos por ejemplo la "novela y escarmiento catorce" de la Guía y aviso de forasteros que vienen a la Corte (1620) de Antonio de Liñán y Verdugo. En esta novela, Roberto, el criado de un caballero, se hace pasar por noble (aunque pobre, caído en desgracia) para seducir a una ingenua Leonarda gracias a un ejemplar de La Diana de Jorge de Montemayor. Roberto la abandona en su huida, llevándose joyas de la

${ }^{1}$ El rol del linaje en los pícaros y sus efectos en el diseño de la novela picaresca como género literario se discuten en Montauban: 48-57. 
muchacha, para que luego ésta llegue a Valencia por sus propios medios, donde se casa con un mercader y logra remediar parcialmente su estado. De esta historia me interesa resaltar el carácter de "tragedia" que para la dueña de la joven Leonarda, llamada Álvarez, tienen los hechos producto de la seducción del ganapán: "Ésta es la tragedia de nuestras locuras, representada en el teatro de nuestros desatinos y mocedades" (Liñán y Verdugo: 262). No lo dice por nada: ella, Álvarez, ha acabado en un burdel de Zaragoza, donde la encuentra don Martín, padre de Leonarda. Cuando finalmente este hombre encuentre a su hija no tendrá menor decepción, ya que la halla en Valencia, amancebada con un tal Bernardo, con quien tiene dos hijos. Frente a tamaña deshonra, que el padre quisiera lavar con la sangre de la hija infamada, a Bernardo, hombre de negocios, no le queda más que casarse con Leonarda, "habiéndose de contentar don Martín, que esperaba un yerno caballero, con un yerno mercader, aunque quien la tuvo por perdida, harto ganada la hallaba, de que daba infinitas gracias a Dios muchas veces" (263). Como se ve, casarla con un mercader en lugar de un caballero (el uso del "don" para don Martín indica que él también lo es) es un mal, aunque menor, ante la afrenta de haber sido desvirgada por un pícaro.

Agreguemos otro ejemplo, aunque con solución diferente. El pícaro amante de José Camerino inaugura al pícaro enamorado que triunfa, aunque sea con una hija de mercaderes ansiosos de ennoblecerse. Es la única forma de hacer verosímil para el lector de la época que tal deshonra y que el amor de la muchacha sean posibles. Ésta es la única historia en donde un pícaro parece salirse con la suya, en tanto puede llevar a cabo un matrimonio por amor (porque el adjetivo amante apunta a eso, "el pícaro que ama") y con una muchacha que deja todo por compartir una vida, aunque en la pobreza, con él. Con razón, Dunn advierte que

the narrator [of El picaro amante], however, expects that the fraud will be exposed before long. In the meantime, the woman's family is to be blamed for being so dazzled by the match that they did not investigate the young man. Significantly, the bride is the daughter of a rich merchant, not of a hereditary nobleman (304). 
De esta forma, la figura del mercader sirve como amortiguador para presentar un conflicto social: la familia de la dama ha perdido toda posibilidad de acceder a la auténtica nobleza. ${ }^{2}$ Hasta podría decidirse que el final de la joven en El pícaro amante expresa la sanción social hacia unos padres que desatendieron su educación.

Ahora bien, nótese que este tipo de matrimonio desigual, donde la mujer es noble (o tan rica que aspira legítimamente a la nobleza) y el varón es plebeyo, era exclusivo en la narrativa de una trama picaresca, si por "picaresca" entendemos una temática (Rey: 81) más que una poética. ${ }^{3}$ En los casos evocados aquí contamos con una narración en donde impera el tono moralizante, con una censura final que intenta resaltar los peligros de no vigilar a las muchachas en edad de merecer frente a los pícaros que desean aprovecharse de ellas. Tal es el caso de la "novela y escarmiento catorce" de la Guía y avisos de forasteros (lección moralista que recogerá la novela de Zayas). En El pícaro amante, igualmente, la mirada crítica está puesta en la familia de la muchacha, que es culpable de la infamia en la que acaba aunque ésta se vea contrarrestada por el supuesto amor que sostiene el enlace, para mayor escándalo de los lectores.

Éstos son los precedentes narrativos de la anécdota central de Amar sólo por vencer. La novela relata el proceso de seducción del pícaro Esteban, quien, fascinado por la adolescente Laurela, se traviste para trabajar como criada suya bajo el nombre de Estefanía. Durante un tiempo, Esteban/Estefanía logra ganarse la confianza de Laurela, hasta revelarle su identidad masculina y declararle su amor, haciéndole creer que es caballero. Laurela escapa con Esteban, quien se aprovecha de ella y la abandona, no sin antes contarle que es un don nadie, un pícaro. La familia de la joven burlada la rescata, la encierra y finalmente le da muerte tirándole una pared encima, para así limpiar la deshonra.

${ }^{2}$ El concepto de "amortiguador humano", entendido como un personaje secundario que contrarresta o "suaviza" la atmósfera pesimista o adversa del mundo recreado para el protagonista (como Sancho Panza en el ambiente picaresco de las ventas donde tiene que salir adelante don Quijote), es desarrollado por Gilman: 99-100.

${ }^{3}$ La excepción la brinda el teatro en una comedia como El perro del hortelano, que incluye una argucia del plebeyo secretario (hacerse pasar por el hijo del viejo conde Ludovico) aceptada por la futura esposa. Aquí la función del enredo, tanto como los horizontes del género comedia, hacen aceptable un final feliz así sobre las tablas. 
Lisa Vollendorf detecta acertadamente que la novela posee dos partes bien diferenciadas: en la primera se cuenta la burla de Esteban, la cual incluye el disfraz femenino, la seducción, la fuga de la pareja, la deshonra y el posterior abandono de Laurela; en la segunda, la reacción de la familia frente a la dama deshonrada y su cruel castigo (183). Podríamos decir que la primera parte de la novela es picaresca, porque se alimenta de sus motivos y su estilo. Si Amar sólo por vencer acabara con la desaparición del pícaro Esteban, no quedaría duda de que es una novela corta de tema picaresco y así habría sido catalogada, tal como la "novela y escarmiento catorce" o El pícaro amante. Es la segunda parte, la venganza perpetrada por la familia de la víctima contra esta última, la que al cerrar la historia le da su carácter eminentemente "zayesco".

¿Cuáles pudieron ser las fuentes literarias de María de Zayas? A mediados del siglo xx hubo una división radical de opiniones. Por un lado, Agustín G. de Amezúa defendía la absoluta originalidad de Zayas, a partir de su supuesta experiencia vital como viajera entre España e Italia, y las constantes referencias, al abrir cada novela, por parte de las figuras narradoras respecto de la veracidad de los hechos contados, hasta el punto de ofrecerlos como testimonios auténticos o casos reales. Con esto, Amezúa propagó el "realismo" de Zayas basado en la declaración de la narradora Lisis de que las historias eran verdaderas o tomadas de la realidad viva (x); evidentemente lo que llamamos "realismo" en tanto mímesis no estaba a discusión. "Realista" en el sentido en que lo usa Amezúa significaría "documentalista" o "testimonial".

Edwin Place, décadas antes de Amezúa y desde la escuela anglosajona, había explorado con la mayor exhaustividad posible las fuentes de las novelas de Zayas. Así, para el motivo del varón que se traviste para acercarse a la dama, Place aportó ejemplos de la novella italiana, a través de autores como Masuccio, Sabadino y Firenzola. Por mi parte, añadiré que quizás la escena más memorable y difundida de un galán vestido de mujer para gozar a la dama es una del Orlando furioso, que tuvo su recreación en El crótalon (aunque resulta dudoso que Zayas conociera este último). ${ }^{4}$ Del resto de acontecimientos en Amar sólo por

${ }^{4}$ El género de los libros de caballerías castellanos incluye algunos ejemplos más en las figuras de Lisuarte de Grecia o Amadís de Grecia, quienes se travisten tanto para se- 
vencer, Place sólo comenta que parecen ser originales, con la particularidad de que Zayas acentúa lo horrible del desenlace para reforzar su mensaje de desengaño (46-47). Lo singular aquí es que el personaje se reconozca como pícaro y que emplee para la seducción el disfraz femenino, el cual poseía en la picaresca un empleo bien distinto al que tiene en la novela de Zayas. Este elemento picaresco mengua la impronta italiana y otorga a la novela su gran originalidad. Nos hallamos así ante la "picaresca" que llevó a cabo María de Zayas en su obra narrativa.

Por ello, pasaré a comentar los elementos picarescos, desatendidos por la crítica, que impregnan esta novela de Zayas. Nuestra autora está bien lejos de poseer una inclinación hacia esa clase de literatura. Su "agenda" narrativa sigue otros cauces, básicamente la novela trágica a la italiana pero puesta al servicio de una causa ideológica: la defensa de las mujeres frente al género masculino. Los hombres son los grandes enemigos en estos relatos; ellos encarnan los vicios (también algunas mujeres perturbadas, que colaboran con ellos), en tanto las protagonistas son víctimas de aquella maldad y violencia, que las convierten en mártires. Amar sólo por vencer resulta singular porque, por lo general, los personajes masculinos de Zayas son caballeros, sujetos nobles aunque viciosos.

Este curioso personaje picaresco de Zayas, Esteban, puede haber surgido de su contacto con Alonso de Castillo Solórzano, fecundo narrador, contemporáneo y admirador suyo, quien compuso obras picarescas, algunas de las cuales parecen ser evocadas creativamente en Amar sólo por vencer. ¿Cuál fue el contacto entre Castillo Solórzano y María de Zayas? Lo seguro es que compartieron el entorno académico de Madrid a inicios de la década de 1620. Piénsese que Castillo Solórzano llegó a ser secretario de la academia de Francisco de Medrano y que por su cargo tenía contacto con todos los ingenios acreditados y los que buscaban alcanzar reconocimiento. Para Pérez-Erdelyi "hay un periodo de diez años (1619-29) en que ambos pertenecían a los mismos círculos literarios donde pudieron llegar a conocerse" (11). En los preliminares

ducir como para alejarse sin llamar la atención. Estas anécdotas galantes caballerescas inspiraron luego elaboradas situaciones festivas en el entorno cortesano (Río Nogueras: 383-402). 
de las Novelas amorosas y ejemplares, el vallisoletano celebra el talento de Zayas con unas décimas — donde la mienta "décima musa"y un soneto, donde la llama "gran Sibila", mote que repetirá en 1642 en su libro La garduña de Sevilla, en el cual la llama "Sibila de Madrid". Más allá todavía, siempre se ha especulado con que el "Prólogo de un desapasionado" (también inserto en las Novelas amorosas y ejemplares) haya sido compuesto por él. No hay prueba de ello, pero sí podría identificársele por la referencia a las academias madrileñas, que - dice el desapasionado - "tanto han aplaudido y celebrado" (Zayas 2000: 163) a Zayas. Es de asumir que sólo un participante en ellas habría sido capaz de afirmarlo. El elogio de las novelas, mezcla de ingenio y moralidades, también parece salido de la pluma de Castillo Solórzano, quien - para la época en que Zayas se estrena como novelista - llevaba varias colecciones bajo el brazo (Tardes entretenidas, Noches de placer, etc.). ¿Qué otro académico podía alabar con conocimiento de causa una colección de novelas si no Castillo Solórzano? Quizás Salas Barbadillo, otro prolífico narrador, pero su personalidad lo condujo a cierto ostracismo a partir de 1625, año en que la carrera de Castillo Solórzano empezó a despegar con la publicación de su primera colección de novelas cortas, Tardes entretenidas. La editora reciente de esta obra, Patricia Campana, considera probable que Zayas haya adaptado el argumento básico, que tiene origen folclórico, de El socorro en el peligro del autor vallisoletano para su novela El imposible vencido. El tema también fue recogido por Lope en su comedia Amar, servir y esperar. Los tres textos tienen en común el tema tradicional de "la difunta pleiteada".

El aire picaresco de Amar sólo por vencer empieza con un urbis encomium de Madrid como "Babilonia de España", cronotopo clásico para ambientar una trama en donde la confusión, el vicio y el asombro permanente imperan. ${ }^{5}$ Una ciudad cosmopolita, "amparo de todas las naciones" porque cobija gente de muy distinto origen; "madre" y "maravilla" porque es un lugar de oportunidades y de constantes cambios, donde se exhiben las nuevas tendencias y las novedades de todas partes

${ }^{5}$ Covarrubias comenta el significado de "Babilonia", recogiendo estas connotaciones: "Al lugar de gran población y de mucho trato, adonde concurren diversas naciones, decimos, por encarecer el tráfago grande que hay y la confusión, que es una Babilonia, especialmente si con esto concurren vicios y pecados que no se castigan” (268). 
del mundo. Este urbis encomium es también el favorito de Castillo Solórzano para describir el ambiente apicarado que enmarca una narración como Las harpias en Madrid (1631): el espacio urbano de la capital que llegó a su apogeo demográfico y cultural durante el reinado de Felipe IV precisamente (1621-1665). Éstas son las palabras de la anciana que convence a doña Teodora para mudarse a Madrid con sus hijas, en aprietos económicos, y medrar:

Es Madrid un maremagno donde todo bajel navega, desde el más poderoso galeón hasta el más humilde y pequeño esquife; es el refugio de todo peregrino viviente, el amparo de todos los que la buscan; su grandeza anima a vivir en ella, su trato hechiza y su confusión alegra. ¿A qué humilde sujeto no engrandece y muda de condición para aspirar a mayor parte? ¿Qué linaje obscuro y bajo no se baptizó con nuevo apellido para pasar plaza de noble? Finalmente, Teodora, la corte es el lugar de los milagros y el centro de las transformaciones (1985: 48).

La "Babilonia", "amparo de todas las naciones", "madre" y "maravilla" de Zayas encuentra sus paralelismos con aquel "maremagno", "refugio" y "lugar de los milagros" que describe Castillo Solórzano: un ancho mar donde convergían gentes de diversa procedencia cuya única meta era enriquecerse y triunfar socialmente. Dos atributos clave del elogio picaresco en Castillo Solórzano son "lugar de los milagros" y "centro de transformaciones", los cuales expresan la facilidad con que podía uno reinventarse y buscar el ascenso social. Zayas no se refiere a la Corte como "centro de transformaciones", pero una alusión a Proteo (que los editores hasta ahora no han entendido) al final del relato nos lo recuerda. La alabanza de la corte como cronotopo da paso a la de Laurela (nombre cuyo significado se revelará al final) y Esteban, criado de un caballero de hábito, pícaro de "comido por servido", hijo de la tierra sin pasado.

Al ver a Laurela, a Esteban se le ocurre un ardid que considera la narradora como "uno de los mayores atrevimientos". Lo cierto es que la situación del travestismo masculino podía ser un tema risible, degradante (caso opuesto al femenino, que era considerado tan sensual como pecaminoso). Aquí la juventud de Esteban hace que el episodio 
sea ambiguo, lúdico, hasta semierótico (en el sentido festivo que tenía el erotismo en el Siglo de Oro) a raíz de los diálogos picantes de esa tensión sexual provocada entre la ingenua Laurela, o incluso los avances del padre de ésta, muerto de amor por Esteban en su faceta de Estefanía, la criada de su hija.

Dado que en las caballerías y en la tradición italiana era posible que un galán se disfrazara de mujer en el contexto de un lance amoroso, el problema de fondo en Amar sólo por vencer es que este galán no es un auténtico caballero galante, sino un pícaro; esto produce reverberaciones narrativas y un grado de parodia seria que el modelo literario caballeresco o italiano no ofrecía. En la novela picaresca, el vestido femenino suele ser una treta para escapar de la cárcel, que aparece ya en la famosa Relación de la cárcel de Sevilla de Cristóbal de Chaves, compuesta a fines del siglo XVI, y de allí debió pasar a la literatura, de la mano del célebre Guzmán de Alfarache (parte II, libro III, cap. VII) de Mateo Alemán. Casi al final de su carrera delictiva, preso en la cárcel sevillana, Guzmán se pone traje femenino para intentar fugarse: "Con una navaja me quité la barba y, vestido, tocado y afeitado el rostro, puesto mi blanco y poco de color, ya cuando quiso anochecer, salí por las dos puertas altas de los corredores" (Alemán: 760); el plan no funcionó porque lo descubre un vigilante tuerto cuando estaba ya por cruzar la puerta principal. Castillo Solórzano reutilizará aquella escena del pícaro fugándose con disfraz femenino, aunque esta vez exitosamente, en La garduña de Sevilla (1642). El falso ermitaño Crispín, una de las víctimas de Rufina, la protagonista, "en hábito de mujer salió a mediodía de la cárcel, con no poca admiración de todos" (Castillo Solórzano 2012: 584). Anteriormente, Castillo Solórzano había recogido la estratagema del pícaro disfrazado de mujer con otros fines. En su novela corta El Proteo de Madrid (incluida en Tardes entretenidas, 1625), el protagonista, el pícaro Domingo, se disfraza dos veces de mujer: una para burlar a un vizcaíno recién llegado y sacarle dinero haciéndose pasar por prostituta y la otra para pedir limosna en apariencia de vieja mendiga. Valgan estos ejemplos como muestra de la vigencia del tópico, empezando con Guzmán de Alfarache, pícaro clásico, y los pícaros modernos de Castillo Solórzano. Dan fe del valor, por eso mismo, del reciclaje que lleva a cabo Zayas de un motivo eminentemente picaresco. 
La transformación de Esteban en Estefanía le permite exhibir su talento como versificador y cantante. Para incidir en su origen picaresco, Esteban, o Estefanía en su faceta femenina, canta una sátira, la cual da paso a la alusión de un motivo picaresco como la crítica de los "dones". El poema que canta para probar su talento es esencialmente picaresco (Zayas 2000: 300-305) por los asuntos que aborda: hurtos, anzuelos, cabelleras, la honestidad que sube al cielo, etc. Estamos ante "a series of contemporary types, tipically satirized in the poetry of the period" (Gorfkle: 80), pero se trata también de materiales presentes en el discurso picaresco: la crítica del falso noble, la alusión a la pobreza proverbial de los poetas y el carácter venal del amor. Mención aparte merece la crítica a las falsas cabelleras (Zayas 2000: 298), ya que además de ser un problema social real es un tema que desarrolló Castillo Solórzano en su novela picaresca Teresa de Manzanares (1632), cuya protagonista es la "moñera" por excelencia, pues se gana la vida confeccionándolas. Encontramos otro posible eco de Castillo Solórzano aquí.

Las situaciones ambiguas y tensas alrededor de Laurela y su criada Estefanía (con celos de ésta incluidos) se van sucediendo. Frente a ello, la gente alrededor ve la relación con curiosidad, hasta el punto que "entre burlas y veras" procuran averiguar el sexo real de Estefanía (Zayas 2000: 318). Este ambiente de "burlas y veras", de verdades a medias, risas y ambigüedades, es el que impera: veras, las del sufrimiento del amante y la reflexión neoplatónica de Laurela; burlas, las de la situación festiva. La tensión dramática llega a la confesión de Esteban, una confesión falsa, la del noble seductor pobre (319-320). El mismo discurso se encuentra en la picaresca de Castillo Solórzano. Lo emplea el pícaro Jaime en La garduña de Sevilla y el noble segundón don Pedro de $E l$ conde de las legumbres (novela incluida en esta última obra). Se trata de galanes que buscan conmover a la dama y ganarse su amor dándole a entender el gran esfuerzo que han hecho para estar a su lado. En particular, el pícaro Esteban resalta ser caballero de Burgos (patria que asegura la mayor nobleza en este contexto literario). Para zafarse del lastre picaresco, ya que Laurela identifica la treta, Esteban porfía en que no es burla, sino que está hablando muy en serio (320). El enojo y la confusión de Laurela frente a esta revelación de su criada la llevan a empuñar una daga para quitarse la vida. 
Frente a este acto desmesurado, Esteban acaba por confesar que todo es "burla" (321), que no haga caso a sus palabras. Esteban/Estefanía urde un engaño (soy caballero pobre) sobre otro engaño (soy mujer). La joven Laurela se va a la cama perturbada, considerando todas las posibilidades de su situación: mantener la mentira, contar a sus padres lo que está pasando, enfrentar a Esteban/Estefanía, descartar todo lo que ha escuchado y casarse (porque tiene un caballero pretendiente, aunque éste no le agrada). Como resultado, Laurela, conmovida ante la historia que le ha contado Esteban/Estefanía sobre su amor, acaba por enamorarse de él porque es pobre, pero también noble y gallardo (322). En un episodio digno de melodrama, Laurela se enferma y Estefanía vuelve a confesarle su identidad de varón noble y su amor. La joven lo acepta, le confiesa que también lo ama y se comprometen a casarse. La narradora

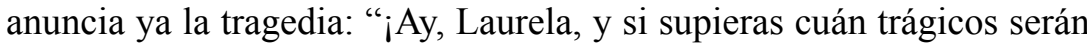
[estos extraños y prodigiosos amores], no hay duda sino que antes te dejaras morir que aceptar tal [palabra de esposo]!” (323).

La fuga se precipita y, ya en una guarida, viene la confesión definitiva de Esteban (325). Es una gran ironía, propia de la picaresca: toda la sátira social que expresaba en su faceta de Estefanía (a través de aquellos poemas satíricos que cantaba tan bien) se vuelve realidad en su propia vida: un pícaro, hijo de un carpintero, supuestamente casado, que se hace pasar por caballero. Dicha ironía también es advertida por Vollendorf:

The great irony (and some might say the great inconsistency) of this tale is that once Esteban reveals his true identity, he proves himself to be just like the men he previously condemned [...] In the end, Esteban reveals all of his lies: he is not a woman, not noble, not single, and not interested in risking his life for Laurela (185). ${ }^{6}$

Todo se viene abajo y se confirma el carácter no-fidedigno de la confesión del pícaro. Habría que preguntarnos por último si algo de lo que

${ }^{6}$ Esta manifestación irónica, de raíz picaresca, puede entenderse también como una expresión del humor de Zayas, aspecto desatendido en su obra, en torno a la cual "se ha dicho hasta la saciedad que es lasciva, inmoral, obscena, violenta, hasta cruel" (Treviño: $x v)$. 
ha confesado Esteban es cierto, porque con los pícaros nunca se sabe. ¿Estará realmente casado o sólo es una excusa para evadir su responsabilidad y que su fuga resulte menos bochornosa? Nunca lo sabremos. Aquí se hace evidente por primera vez el título: Amar por el placer de vencer, de burlar o someter a la dama noble, que cae en su engaño. Esa es su gran victoria. Se escapa para preservar la vida y la deja abandonada, burlada. El que el pícaro se aferre a la vida también es un detalle a tener en cuenta pensando en el final trágico de la propia Laurela. Descubierto el escándalo por la familia, el padre prefiere mantener en silencio la deshonra de la muchacha y ésta se queda viviendo en casa de su tía.

Hasta aquí llega la picaresca, porque el resto de la novela se enfoca en Laurela, en su encierro, olvidada ya de la alegría que la caracterizaba, porque en ella se encuentra el origen de su desgracia (Zayas 2000: 329). El padre y el tío (siempre los hombres) desencajan un tabique para que la pared caiga sobre Laurela y la mate. Lo logran. La criada escucha el veredicto condenatorio de los hombres fuertes de la familia: "Páguelo la traidora, que se dejó engañar y vencer, pues no hemos podido hallar al engañador, para que lo pagaran juntos" (330). El pícaro logra escapar y triunfa, sus aventuras siempre prosiguen. Fiel a su vocación, rehúye la muerte.

Cervantes fue uno de los primeros lectores que detectaron este rasgo (el del pícaro que siempre escapa) y lo reflejó en su personaje Ginés de Pasamonte, quien aparece en el capítulo XXII de la Primera parte del Quijote. El libro del pícaro, titulado La vida de Ginés de Pasamonte, nunca queda concluido, porque su protagonista jamás se detiene. “¿Cómo puede estar acabado — respondió él—, si aún no está acabada mi vida?”, replica el pícaro a don Quijote cuando éste le pregunta si ya terminó de escribirlo (Cervantes 2004: 206). El libro de Ginés de Pasamonte queda fragmentado, incompleto, tanto como su propia vida, saltando de aventura en aventura (Spadaccini: 214). Sólo la muerte o la conversión religiosa pueden ofrecer la conclusión de un libro picaresco; pero si el pícaro muere no tenemos libro. En la Segunda parte del Quijote, Ginés vuelve a aparecer, como Maese Pedro, y podemos imaginarlo con nuevos disfraces, en cualquier otra trama, entrando y saliendo del escenario.

Valga esta digresión sobre la vida del pícaro, condenado a la vida errante, para comprender la desaparición de Esteban en Amar sólo por 
vencer, aparentemente al margen de su desenlace. Porque esto nos lleva al aspecto trágico de la novela de Zayas, la atmósfera de violencia feroz que lleva a la muerte a la protagonista, Laurela, un tema totalmente ajeno a la picaresca. En esta última, al pícaro le repugna el ataque a mano armada y todo lo que tenga que ver con matar: "No son materia picaresca los crímenes de sangre" (Bataillon: 14). ¿Por qué ocurre esto? Peter Dunn explica que el pícaro reprime la violencia mediante el uso del humor, que la aligera, reduciéndola a los golpes típicos de la comedia antigua. Para la mentalidad de la época áurea, "death is still heroic or tragic or exemplary, in literature as in painting" (311). Porque el pícaro, en verdad, pretende ser un artista, un tipo de manos ágiles o un impostor profesional (Esteban lo demuestra muy bien), pero nunca se confunde con el valentón o matachín a lo Escarramán o germano. ${ }^{7}$ El pícaro Esteban vence, triunfa, ve la vida como una competencia y así lo advierte la narradora formulando un consejo para el auditorio femenino: "No fiarse de los bien fingidos engaños de los cautelosos amantes que no les dura la voluntad más de hasta vencerlas" (Zayas 2000: 331).

El mensaje de la narradora se aplica a todos los hombres, no a los pícaros en particular, y eso significa una superación de Zayas con respecto a los elementos que ha recogido. Puso la picaresca al servicio de su propio compromiso literario: "Laurela" viene de laurel, la señal de la victoria, una parodia de las aventuras picarescas que en el plano amoroso nunca funcionan; piénsese en la connotación lírica que tenía el laurel como premio al más leal amante. El pícaro ni es leal ni es amante de verdad. Toda su carrera está basada en el engaño. Y todos los Desengaños amorosos se ocupan de este asunto: cómo los hombres urden engaños y cómo las mujeres han de descubrirlos a tiempo. Veamos ahora cómo Zayas aborda el engaño de la picaresca y le da un alcance mayor. Ya que el pícaro es el máximo engañador.

El hombre galante, engañador, según la narradora, hace más "transformaciones que Proteo por traer una mujer a vuestra voluntad" (331332). Todas las ediciones leen Prometeo, errata evidente que nadie ha

${ }^{7}$ Pablos de Segovia tiene un breve periodo como bravo en Sevilla, cuando conoce a la Grajales; pero es el momento exactamente previo a su viaje a América y al final de su libro, cuando vuelve a desaparecer del escenario con la promesa de proseguir sus aventuras en la segunda parte (inexistente) del Buscón. 
corregido hasta ahora. ${ }^{8}$ Margaret Greer ya lo advirtió en su estudio sobre Zayas (225), pero atribuye (y respeta) el error por venir de la propia autora. ${ }^{9}$ No tenemos la certeza de que Zayas cometiera el error o que fuera intencional, en todo caso, confundir a Prometeo con Proteo en un pasaje que sólo se entiende refiriéndose a este último personaje. ${ }^{10}$ Por ello es conveniente, para que el pasaje tenga su cabal sentido, enmendar por "Proteo".

No es coincidencia que Proteo sea uno de los dioses que mencionan narradores y lectores de la picaresca para aludir a los tantos disfraces del pícaro. La imagen tuvo gran éxito desde la aparición del Guzmán de Alfarache, a quien se le atribuye ser un Proteo por sus múltiples oficios, como buen pícaro que se busca la vida. Se le llama Proteo tanto en los preliminares de la segunda parte de 1604 como en las traducciones francesa e inglesa contemporáneas (Cros: 88-89). ${ }^{11}$ Castillo Solórzano honró esta identificación picaresca en El Proteo de Madrid (novela corta incluida en su colección Tardes entretenidas), donde la identificación ya es absoluta. Aquí "Proteo" significa pícaro, y designa al protagonista, Domingo: entre sus muchas identidades aparecen la de paje, soldado

8 "Haréis más transformaciones que Prometeo" (Zayas 2001: 614), reza la edición de Obra narrativa completa en Biblioteca Castro. Lo mismo la edición que empleo yo, de Alicia Yllera (Zayas 2000), aunque para la cita ya la he corregido.

9 Este respeto a la supuesta voluntad del autor también surge en un pasaje del Quijote. En el episodio del mozo Andrés y Juan Haldudo (parte I, cap. IV), en la princeps se lee "setenta y tres" cuando el resultado de la multiplicación ("nueve meses a siete reales cada mes") debe arrojar "sesenta y tres". La edición clásica de Martín de Riquer conserva "setenta y tres" y lo justifica en nota a pie de página, interpretando el pasaje como una "equivocación que intencionalmente Cervantes hace cometer a don Quijote, tan sabio en armas y en letras, equivocación que, naturalmente, favorece al menesteroso" (Cervantes 1985: 57). La edición de Francisco Rico mantiene la lectura "setenta y tres", pero deja abierta la interpretación en nota al pie: "Como puede comprobarse, son sesenta y tres: ¿error de don Quijote o de Cervantes? ¿O quizá errata?” (2004: 49).

${ }^{10}$ Sin embargo, es cierto que en otra ocasión Zayas confunde personajes mitológicos. En la misma Amar sólo por vencer, Zayas llama "Teseo" a un personaje que es claramente Prometeo, pues le pide contar "la pena que padeces en el Cáucaso feo" (Zayas 2000: 315). Visto así, la escritora tendría las referencias mitológicas cruzadas: creería que Prometeo era Teseo y que Proteo era Prometeo.

${ }^{11}$ Alfonso Rey comenta este carácter proteico del pícaro (107). Además, Edmond Cros (335-350) ahonda en torno al "polimorfismo" de Guzmán. 
y clérigo, además de travestirse, como ya se indicó, de dama y de vieja mendiga.

Greer advierte que "transformarse" no aparece en otras historias que incluyen disfraz que supone cambio de género, pero aparece constantemente (hasta seis veces) en este relato (220). Por ende, debemos pensar que el verbo y su sustantivo asociado, "transformación", tienen origen picaresco, como lo atestiguaba el encomio de Madrid como "centro de transformaciones", según lo proponía Las harpías en Madrid de Casti1lo Solórzano. Baltasar Gracián, en el mismo año cuando publica Zayas los Desengaños, emplea la figura de Proteo en su Oráculo manual (1647) para dar advertencias cortesanas y políticas, un ambiente de relaciones en donde el pícaro también había participado, por lo que pícaro y cortesano son como el haz y el envés de una conducta acomodaticia, de doble moral: "Discreto Proteo: con el docto, docto, y con el santo, santo. Gran arte de ganar a todos, porque la semejanza concilia benevolencia" (145). ${ }^{12}$ Lo original entonces en Zayas es adoptar el mote de Proteo, de origen picaresco, para calificar la conducta amorosa de los varones. Nuevamente desplaza las connotaciones convencionales de su época (ora picaresca o cortesana) para llevar agua a su molino: la defensa del género femenino.

De tal forma, Zayas recoge todos esos materiales de la picaresca, que quizás adoptó de Castillo Solórzano, a quien parece haber leído bien: el elogio de Madrid como "centro de transformaciones" (con las constantes alusiones a este sustantivo, así como el Proteo del final, que enlaza con aquel "Proteo de Madrid" del autor vallisoletano); los temas de crítica social picarescos que también tocó Castillo Solórzano (las cabelleras postizas), el disfraz femenino del pícaro, la figura (aunque falsa) del galán noble y pobre, etc. Dichos materiales son asumidos y procesados por Zayas, quien no se conforma con imitar. Greer concluye que en Amar sólo por vencer el destino fatal de Laurela se produce por

${ }^{12}$ Más allá todavía, en El criticón (parte I, crisi VII), Gracián hace aparecer al monstruo Proteo, de múltiples formas, cuando los personajes pasan por la fuente de los Engaños y se encuentran con una ciudad donde se representan, de manera alegórica, vicios asociados al mundo cortesano y también a la picaresca, como la hipocresía o la falsa ostentación. Nuevamente, el autor asocia la figura mitológica de Proteo con el engaño y su función en la sociedad. Debo esta referencia de El criticón a Aurora González Roldán. 
transgredir límites tanto genéricos como sociales (226). Existe también una convención picaresca (estafar y huir), que Zayas desplaza (tal como se va Esteban, se desvanece) y supera, porque se pone en primer plano el desenlace que espera a la víctima, un acto de violencia contra la mujer a manos de quienes deberían protegerla.

Es este desenlace trágico lo que opaca la ironía picaresca hasta diluirla. Recordemos la confesión de Esteban: ¿cómo criticar los vicios de la sociedad, asumiendo una postura moralista, cuando el mismo enunciador ha practicado esos vicios? La paradoja picaresca (la misma del mentiroso cretense) no llega a poner en riesgo el mensaje de Amar sólo por vencer, dado que es anulada por la muerte de la joven, víctima del engaño del pícaro pero también de la familia, que finge cobijarla hasta poder tenderle la trampa, para que todo parezca un accidente, y acabar con su vida. La muerte de Laurela termina con cualquier tipo de ambigüedad promovida por el pícaro, que siempre escapa gracias a su escritura. Sus actos tendrán una consecuencia, un castigo, aun cuando lo sufrirá otra persona, su propia víctima: "Aunque el acto de asesinato de la protagonista sea tramado por don Bernardo, en connivencia con su hermana y cuñado, podemos afirmar que ha sido el despiadado Esteban quien la ha puesto en el camino que lleva a la destrucción, a la muerte definitiva" (García Gavilán: 290). En suma, Zayas recogió este y otros materiales de la picaresca, tanto anecdóticos como ideológicos, para incorporarlos a su narración de Amar sólo por vencer, reciclándolos y dotándolos de un nuevo significado. Así, la novelista pone en primer plano un aspecto que nunca cubre la tradición picaresca, gestada por autores masculinos, en torno a este tema: el destino aciago de la mujer burlada.

\section{BIBLIOGRAFÍA}

Alemán, Mateo. La obra completa, 3. Guzmán de Alfarache. David Mañero Lozano (ed.). Madrid-Franfkurt am Main: Iberoamericana-Vervuert, 2014. Amezúa, Agustín G. DE. "Prólogo", en María de Zayas. Desengaños amorosos. Parte segunda del sarao y entretenimiento honesto. Agustín G. de Amezúa (ed.). Madrid: Biblioteca Selecta de Clásicos Españoles, 1950: vii- xxiv. 
Bataillon, Marcel. Pícaros y picaresca. La picara Justina. Madrid: Taurus, 1969.

CAMERINo, José. "El pícaro amante", en Novelas amorosas de diversos ingenios del siglo XVII. Evangelina Rodríguez Cuadros (ed.). Madrid: Castalia, 1986: 93-108.

Castillo Solórzano, Alonso De. Las harpías en Madrid. Pablo Jauralde (ed.). Madrid: Castalia, 1985.

Castillo Solórzano, Alonso de. Tardes entretenidas. Patricia Campana (ed.). Barcelona: Montesinos, 1992.

Castillo Solórzano, Alonso de. Picaresca femenina de Alonso de Castillo Solórzano. Estudio y edición de "Teresa de Manzanares" y "La garduña de Sevilla". Fernando Rodríguez Mansilla (ed.). Madrid-Frankfurt am Main: Iberoamericana-Vervuert, 2012.

Cervantes, Miguel De. El ingenioso hidalgo don Quijote de la Mancha. Martín de Riquer (ed.). Madrid: Cupsa Editorial, 1977.

Cervantes, Miguel De. El ingenioso hidalgo don Quijote de la Mancha. Francisco Rico (ed.). Madrid: Real Academia Española, 2004.

CovarRubias, Sebastián DE. Tesoro de la lengua castellana o española. Ignacio Arellano y Rafael Zafra (eds.). Madrid-Frankfurt am Main: Iberoamericana-Vervuert, 2006.

Cros, Edmond. Protée et le gueux. Recherches sur les origines et la nature du récit picaresque dans Guzmán de Alfarache. Paris: Didier, 1967.

Dunn, Peter. Spanish Picaresque Fiction. A New Literary History. Ithaca: Cornell University Press, 1993.

García GaVILÁn, InMACULADA. "El cuerpo femenino como metáfora en Amar sólo por vencer de María de Zayas y Sotomayor", en Estudios humanísticos. Filología, 23 (2001): 279-292.

Gilman, Stephen. La novela según Cervantes. México: Fondo de Cultura Económica, 1993.

GorfKLe, LaURa. "Re-constituing the Feminine in Amar sólo por vencer", en Maria de Zayas. The Dynamics of Discourse. A. R. Williamsen y J. A. Whitenack (eds.). Madison \& London: Associated University Presses, 1995: 75-89.

Gracián, Baltasar. Oráculo manual y arte de prudencia. Emilio Blanco (ed.). Madrid: Cátedra, 2000.

Greer, Margaret. María de Zayas Tells Baroque Tales of Love and the Cruelty of Men. University Park: The Pennsylvania State University Press, 2000.

Liñán y Verdugo, ANTONIO. Guía y avisos de forasteros que vienen a la Corte. Edison Simons (ed.). Madrid: Editora Nacional, 1980. 
Montauban, JANnine. El ajuar de la vida picaresca. Reproducción, genealogía y sexualidad en la novela picaresca española. Madrid: Visor Libros, 2003.

PéreZ-ERdelyi, Mireya. La pícara y la dama. La imagen de las mujeres en las novelas picaresco-cortesanas de María de Zayas y Sotomayor y Alonso de Castillo Solórzano. Miami: Ediciones Universal, 1979.

Place, Edwin N. "María de Zayas, an Outstanding Woman Short-Story Writer of Seventeenth Century Spain", en University of Colorado Studies, 13:1 (1923): 1-56.

Rey, Alfonso. Lectura del "Buscón”. Valladolid: Colección Fastiginia, 2014.

Río Nogueras, Alberto Del. "Libros de caballerías y fiesta nobiliaria", en Amadís de Gaula, 1508: quinientos años de libros de caballerías. Madrid: Biblioteca Nacional de España-Sociedad Estatal de Conmemoraciones Culturales, 2008: 383-402.

Spadaccini, Nicholas. "Estebanillo González and the Nature of Picaresque Lives", en Comparative Literature, 30 (1978): 209-222.

TreviÑo, Elizabeth. "Introducción", en María de Zayas. Amar sólo por vencer. Elizabeth Treviño (ed.). México: Universidad Nacional Autónoma de México, 2014: vii-xxi.

Vollendorf, Lisa. Reclaiming the Body. María de Zayas 's Early Modern Feminism. Chapel Hill: North Carolina Studies in the Romance Languages and Literatures, 2001.

ZAYAS, MARÍA DE. Desengaños amorosos. Alicia Yllera (ed.). Madrid: Cátedra, 2000.

ZAYAS, MARÍA DE. Obra narrativa completa. Estrella Ruiz-Gálvez Priego (ed.). Madrid: Biblioteca Castro, 2001. 